\title{
Design and Optimization of Comb Drive Accelerator for High Frequency Oscillation
}

\author{
Zichen Zhang \\ Shandong Experimental High School, Jinan, China \\ Email:2265981775@qq.com
}

How to cite this paper: Zhang, Z.C. (2018) Design and Optimization of Comb Drive Accelerator for High Frequency Oscillation. Modern Mechanical Engineering, 8, 1-10. https://doi.org/10.4236/mme.2018.81001

Received: November 6, 2017

Accepted: January 14, 2018

Published: January 17, 2018

Copyright $\odot 2018$ by author and Scientific Research Publishing Inc. This work is licensed under the Creative Commons Attribution International License (CC BY 4.0).

http://creativecommons.org/licenses/by/4.0/

\section{cc) (i) Open Access}

\begin{abstract}
Comb-drive devises have been widely applied in many fields. However, the application of high frequency sensor, such as rocket chamber, still remains problems. In this work, a finite element code was used for the design, optimization and visualization of a comb drive accelerator. In the simulation results, the post-optimization design has high performance in high frequency oscillation operating environment. The optimization is based on the ideal eigenfrequency and Nelder-Mead method. The 3-D working conditions are realized by testing and comparing the time and frequency domain of pre-optimized and optimized design whose frequency ranges from $2000 \mathrm{~Hz}$ to $5000 \mathrm{~Hz}$. Finally, the electric potential and capacitance in comb drive are visualized, which shows the better electric signals and displacements.
\end{abstract}

\section{Keywords}

Comb-Drive Micro-Structure, COMSOL Multiphysics, Optimization, Electric Responses

\section{Introduction}

In contemporary society, the Micro-Electro-Mechanical System (MEMS) devices play a significant role in many fields, e.g. accelerator, fluid control, micro-power system, MEMS fuse system and internet of things (IOT) [1]. The widely use of MEMS devices is due to its scaling advantage, i.e. the scaling of MEMS devices reduces the cost per device. Although the total cost to fabricate one wafer may increase, the number of devices on each wafer increases exponentially with the decrease of the feature size of MEMS devices. In addition, the finer fabrication process provides high performance of MEMS devices. For example, the accuracy and precision of MEMS sensors are orders of magnitude higher than conventional sensors [2]. Therefore, MEMS becomes a focus of both fundamental re- 
search and applicable engineering. Among all the MEMS applications, the comb drive uses electrostatic force as the actuation principle. There are two metal conductors in the micro-scale shape of the comb. They both alternate with each other where one is static and the other is dynamic. When passing an alternating current, one of the combs will be moving which is relative to another conductor. More specifically, more and more scientists prefer to use the comb drives for electrostatic actuation, capacitive position sensing and frequency turning [3]. They have become an inalienable part of many MEMS devices such as accelerometers, gyroscopes, and micro scanners and so forth [4]. The rocket combusting chamber has a specific vibrating frequency, which is usually within the range from 1000 to $5000 \mathrm{~Hz}$. The design and development of a micro-accelerator become an essential problem for real-time monitor of the working stators of the combusting chamber.

However, the design and optimization of comb drive sensor become a challenge for the society since the geometry of the devices is complex. Xie et al. has already designed and fabricated the out of plane comb drives which can achieve the aim of realizing [5]. Based on Xie's design, some scientists have already successfully developed and tested 1-D analog scanning micro mirror arrays with hidden vertical comb-drive actuators [6]. Besides, there are also some other groups using comb drive to solve out sophisticated problems as to overcome the difficulties of isolating two stationary capacitor comb sets in bulk micromachining by the electrically [7]. Whereas, those designs lack of the freedom to change all the parameters of the comb drive, which means that the designs are partially fixed. Moreover, there is no visualization in their models, making it hard to show the results of the model.

In this work, I used the powerful simulation software-COMSOL to make the model more vivid and visual. The study of the vertical comb-finger actuation for CMOS MEMS is also been realized, simulated and tested. In addition, behavioral simulation using the 3-D NODAS library matched the experimental results within $7 \%$ for frequency response. Comparing with this work, the frequency domain study was conducted to optimize the model which nobody has involved in this filed. I also parameterized the geometry of the comb drive structure, e.g. fingers and stators. As a result, I can easily change the structure for optimization in the model. In this way, the model can solve the problems that have mentioned above.

\section{Model Setup}

The schematic of the comb drive used in this work is shown in Figure 1, in which (a) and (b) show the plane and the stereoscopic geometry respectively. Parameterization makes it easy to change the specific numerical number of different parts. In Figure 1(a), the comb drive has five fingers in both the static (right) and moving (left) combs. To better describe the structure, I use $\boldsymbol{w}$ to represent the width of stators $(s t)$, fingers $(f)$ or spring $(s p), I$ to represents the 


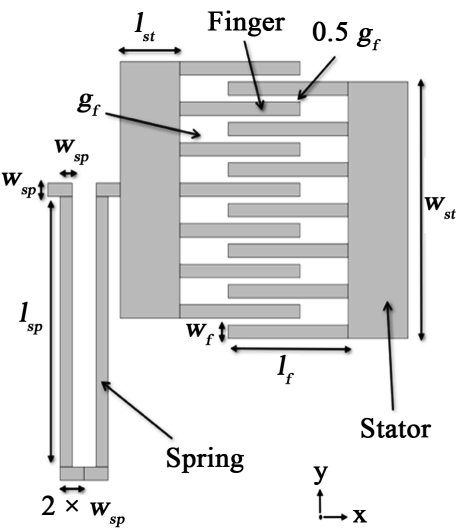

(a)

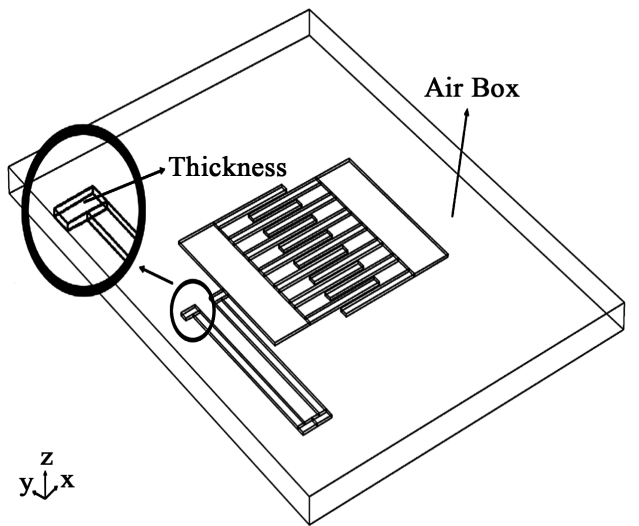

(b)

Figure 1. (a) 2-D plane schematic of the comb drive; (b) 3-D stereoscopic schematic of the comb drive.

length, and $\boldsymbol{g}$ for gaps between two fingers. In order to stimulate the real working circumstance of comb drives, Figure 1(b) shows the thickness of structures, and the air box as the air around the comb drive in three dimensions. The airbox is setup to calculate the electric field in the air. In order to adapt the rocket chamber circumstances, the number of fingers is fixed as five, the material is copper, and environment is $293.15 \mathrm{~K}$ for temperature, 1 atm for absolute pressure which have been all set up in COMSOL.

Before the optimization, each parameter is set up the proper number, as 200 $\mu \mathrm{m}$ for $l_{f}, w_{f} 20 \mu \mathrm{m}, l_{s t} 100 \mu \mathrm{m}, g_{f} 20 \mu \mathrm{m}, l_{s p} 400 \mu \mathrm{m}, w_{s p} 20 \mu \mathrm{m}$, and $w_{s t}$ expresses as:

$$
w_{s t}=6 w_{f}+5\left(g_{f}+w_{f}\right)
$$

which can derive that $w_{s t}$ is $380 \mu \mathrm{m}$. On the other hand, the thickness is $5 \mu \mathrm{m}$, and the size of air box is large enough to cover the whole model.

After fixing the right stator, I apply an oscillating voltage with $1 \mathrm{~V}$ amplitude to the left comb. The relation between the displacement, $u$, and the time domain, $t$, which is the first $1 \mathrm{~ms}$, can be easily obtained by solving the equation below:

$$
\rho \ddot{u}=\nabla \cdot s+F_{V}
$$

where $\rho$ is the density, $s$ is the stress tensor and $F_{V}$ is the external force density.

Figure 2 shows the displacement of the moving comb after applying an oscillating voltage at the comb drive by applying $1 \mathrm{~V}$.

Then we simulate the deformation of the moving comb in the frequency domain. The frequency ranges from $2000 \mathrm{~Hz}$ to $5000 \mathrm{~Hz}$, which is the average frequency of the rocket, is used to calculate the displacement, $u$. The inertia force applied on the moving comb is set to be constant. We expect the larger displacement with the same inertia force amplitude since the larger displacement can induce more significant electric signal change. Thus, we can optimize the structure in order to obtain the maximum displacement in the frequency where 


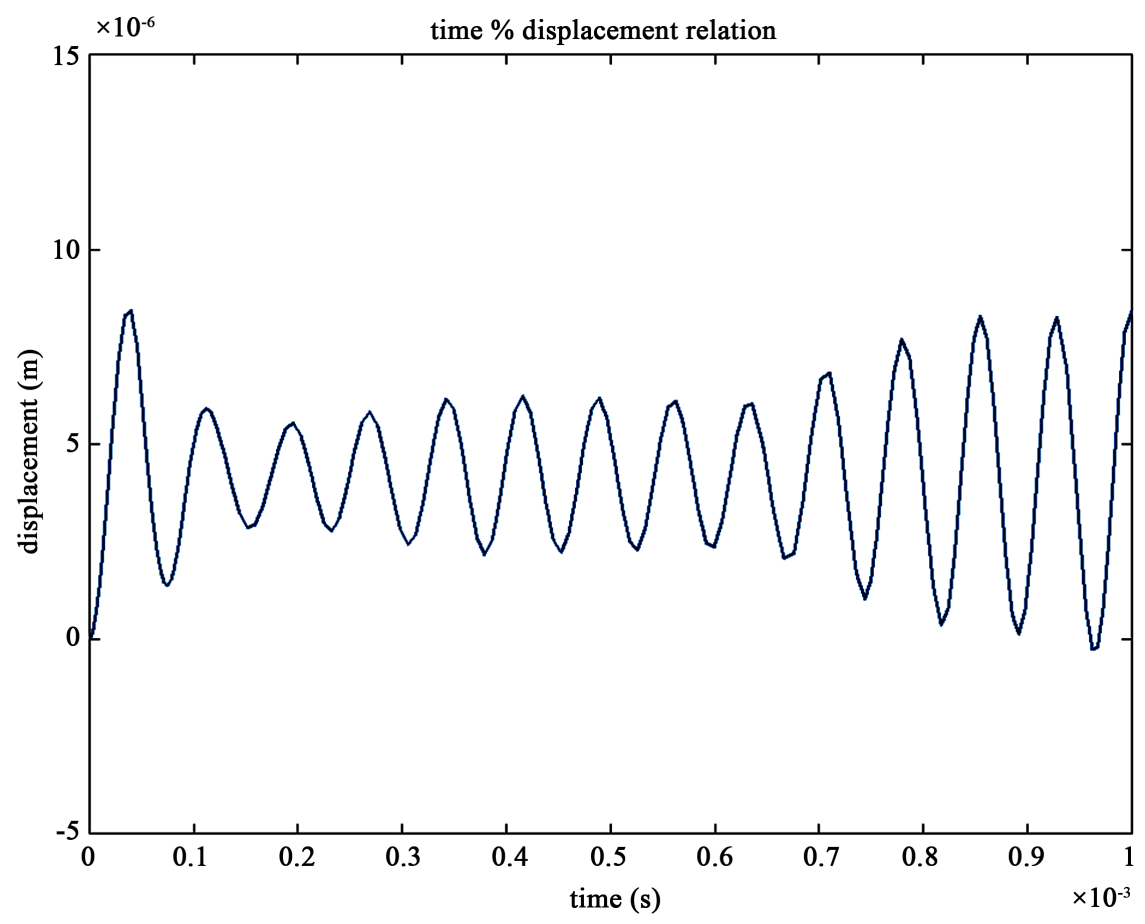

Figure 2. The initial relation between displacement and the time.

the rocket chamber operates. In the end, we compare this pre-optimized design $(P D)$ to with the optimized design $(O D)$ to show the improvement of the device.

Different displacement fields with different frequencies (freq) are shown in Figures 3(a)-(d). The volume color represents the displacement field for each part.

\section{Result}

First, the eigen modes of the mechanics are evaluated. As widely known, the rocket chamber operating frequency has a range from $5000-10,000 \mathrm{~Hz}$, which is our objective frequency. The eigenfrequency should be as close as the objective to output the maximum displacement. For the physical material, the specific frequency which reachs the maximum amplitude is called Eigenfrequency. Before the optimization, the eigen frequencies of the pre-optimized design's (PD) are far away from $5000 \mathrm{~Hz}$ which is the operation frequency of the rocket chamber. As a result of the frequency mismatch, the performance of the PD is not considered appropriate for the rocket chamber application. Figure 4 shows two the eigen modes of device. The colors in Figure 4 represent the displacement field of the drive.

To compare these two different modes, the second eigen mode (Figure 4(b)) has translational motion of the left comb with $13,587 \mathrm{~Hz}$. It should be mentioned that we expect the translational mode rather than other modes. In translational mode, all the left fingers move toward the stator coherently.

The optimization used Nelder-Mead method to obtain a better performance of the comb drive accelerator. The variable in the optimization is the length of 


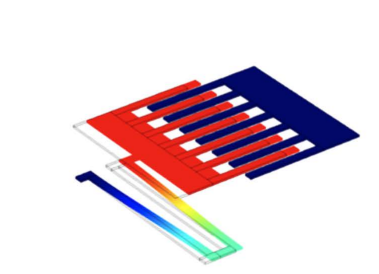

(a)

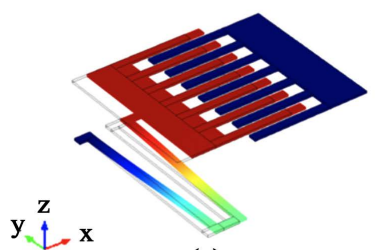

(c)

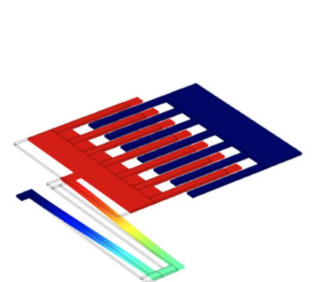

(b)

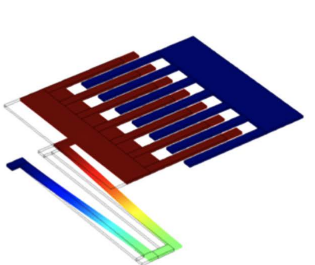

(d)

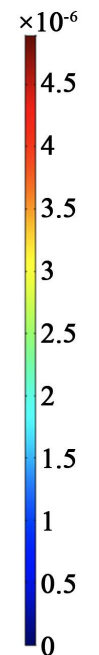

Figure 3. (a), (b), (c), and (d) reflect the visualized displacement by colors when frequency is $2000 \mathrm{~Hz}, 3000 \mathrm{~Hz}, 4000 \mathrm{~Hz}$ and $5000 \mathrm{~Hz}$ respectively.

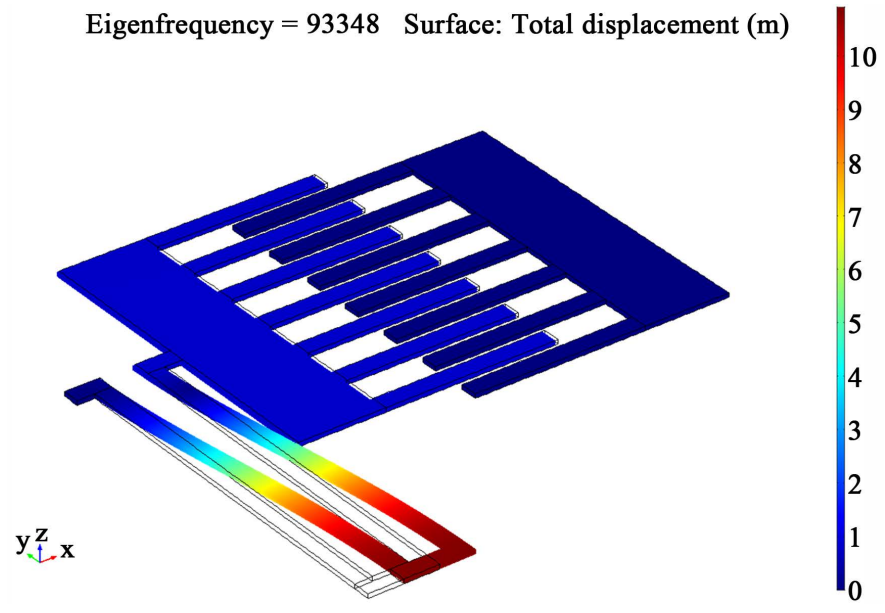

(a)

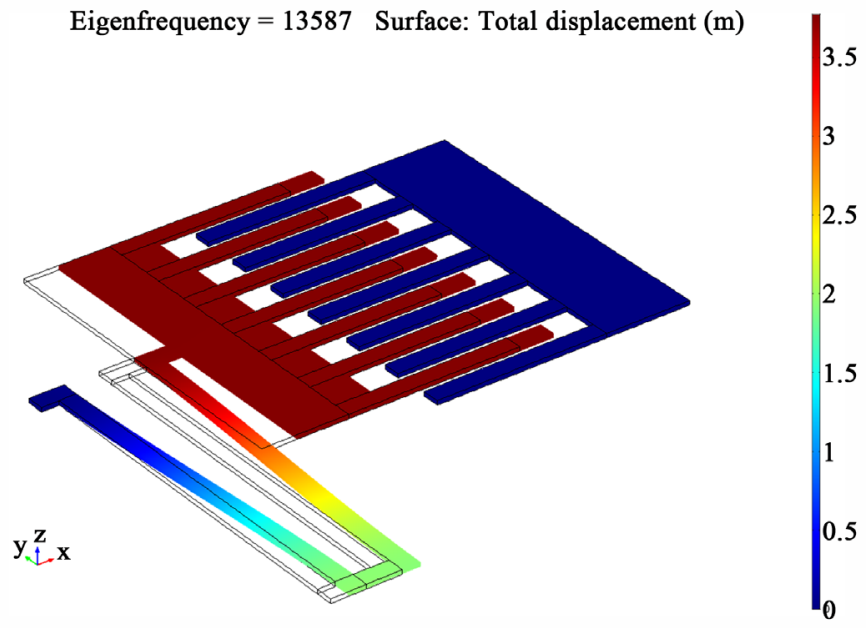

(b)

Figure 4. (a), (b) show two different working performance of two Eigenfrequency around 10,000 Hz. 
the suspension spring. The constraint boundary of the optimization is set up to vary from $180 \mu \mathrm{m}$ to $200 \mu \mathrm{m}$, while varying from $80 \mu \mathrm{m}$ to $120 \mu \mathrm{m}$. The goal of the optimization is to get the frequency of the translational mode to as close as $10,000 \mathrm{~Hz}$. Therefore, the objective of the optimization is the square of the difference between the translational mode frequency and the designated 10,000 $\mathrm{Hz}$. The math is to minimize this objective while using different geometries of the comb drive. Represented results of the optimization are shown in Table 1.

It can be found that, when equals to $2 \mu \mathrm{m}$ with $1.2 \mu \mathrm{m}$, the eigenfrequency is closest to the $10,000 \mathrm{~Hz}$ where our design goal is achieved.

After adapting all the parameters from the optimization, we built the optimized design (OD) and tested the new design to compare its performance with our original design. Comparison of the displacement is shown in Table 2. Figure 5 shows the difference performance between PD and OD in the frequency range of the rocket chamber.

Table 1. The optimization results.

\begin{tabular}{cccc}
\hline The optimization results & $l_{\text {finger }}(\mathrm{m})$ & $l_{\text {stator }}(\mathrm{m})$ & Objective \\
\hline $2.00 \times 10^{-4}$ & $1.00 \times 10^{-4}$ & $1.2869 \times 10^{7}$ \\
$1.98 \times 10^{-4}$ & $1.00 \times 10^{-4}$ & $1.3063 \times 10^{7}$ \\
$2.00 \times 10^{-4}$ & $1.02 \times 10^{-4}$ & $1.2370 \times 10^{7}$ \\
$1.96 \times 10^{-4}$ & $1.00 \times 10^{-4}$ & $1.3250 \times 10^{7}$ \\
$2.00 \times 10^{-4}$ & $9.80 \times 10^{-5}$ & $1.3389 \times 10^{7}$ \\
$2.00 \times 10^{-4}$ & $1.20 \times 10^{-4}$ & $8.5970 \times 10^{6}$ \\
\hline
\end{tabular}

Table 2. The relation between frequency and displacement of PD and OD.

\begin{tabular}{cccc}
\hline $\begin{array}{c}\text { The relation between } \\
\text { frequency and } \\
\text { displacement } \\
\text { of PD and OD }\end{array}$ & $\begin{array}{c}\text { Frequency } \\
(\mathrm{Hz})\end{array}$ & $\begin{array}{c}\text { PD Displacement } \\
(\mathrm{m})\end{array}$ & $\begin{array}{c}\text { OD Displacement } \\
(\mathrm{m})\end{array}$ \\
\hline & 2000 & $4.3095 \times 10^{-6}$ & $4.3171 \times 10^{-6}$ \\
2250 & $4.3350 \times 10^{-6}$ & $4.3453 \times 10^{-6}$ \\
2500 & $4.3638 \times 10^{-6}$ & $4.3773 \times 10^{-6}$ \\
2750 & $4.3961 \times 10^{-6}$ & $4.4133 \times 10^{-6}$ \\
& 3000 & $4.4321 \times 10^{-6}$ & $4.4533 \times 10^{-6}$ \\
& 3250 & $4.4718 \times 10^{-6}$ & $4.4977 \times 10^{-6}$ \\
& 3500 & $4.5156 \times 10^{-6}$ & $4.5467 \times 10^{-6}$ \\
& 3750 & $4.5635 \times 10^{-6}$ & $4.6004 \times 10^{-6}$ \\
& 4000 & $4.6159 \times 10^{-6}$ & $4.6593 \times 10^{-6}$ \\
& 4250 & $4.6730 \times 10^{-6}$ & $4.7237 \times 10^{-6}$ \\
4500 & $4.7351 \times 10^{-6}$ & $4.7939 \times 10^{-6}$ \\
& 4750 & $4.8027 \times 10^{-6}$ & $4.8705 \times 10^{-6}$ \\
& 5000 & $4.8759 \times 10^{-6}$ & $4.9539 \times 10^{-6}$ \\
\hline
\end{tabular}




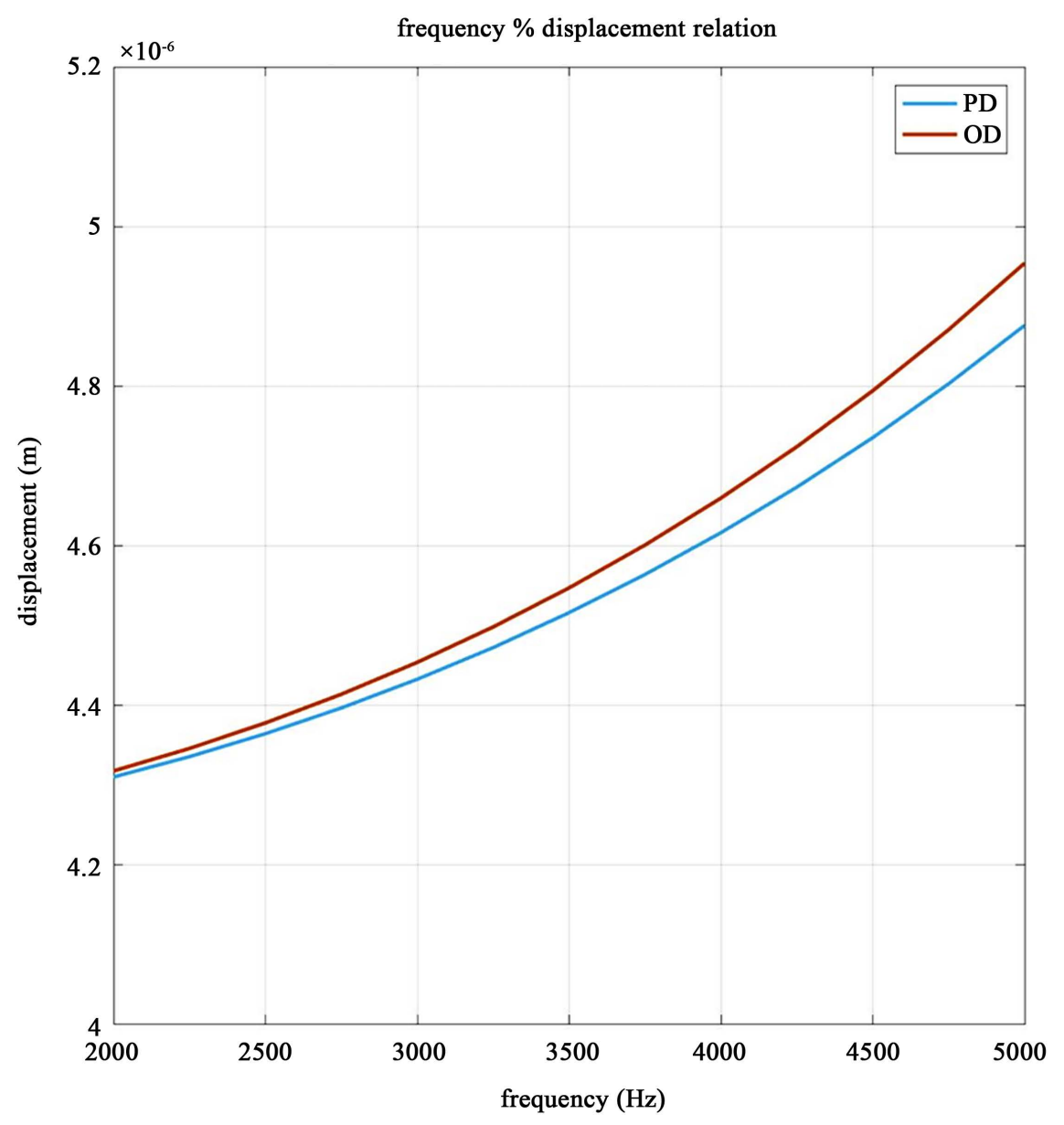

Figure 5. Relation between frequency and displacement of PD and OD.

Next, we simulated the relation between the applied forces and displacements. The results of frequency dependent displacement are presented in Table 3. By applying the same force, the OD had significantly larger displacement than that of PD. Thus, the simple test proves that the displacement has ascended after optimization. Even only a small increase in the displacement, it will increase the electric signal on the micro level.

In the static electric domain, the electric field $E$ satisfies the following relation

$$
\begin{gathered}
\boldsymbol{E}=-\nabla V \\
\nabla \cdot \varepsilon_{0} \varepsilon_{r} E=\rho_{v}
\end{gathered}
$$

where $V$ is the electric potential, $\varepsilon$ is the permittivity and $\rho_{v}$ is the electric charge density. The capacitance of the device can be calculated as $C=Q / V=3.2581 \times 10^{-14} \mathrm{~F}$, if the device is in static.

Figure 6 shows the capacitance versus the length of the overlap which is induced by the external force. The capacitance can be simply estimated with the equation

$$
C=\frac{\varepsilon S}{d}
$$




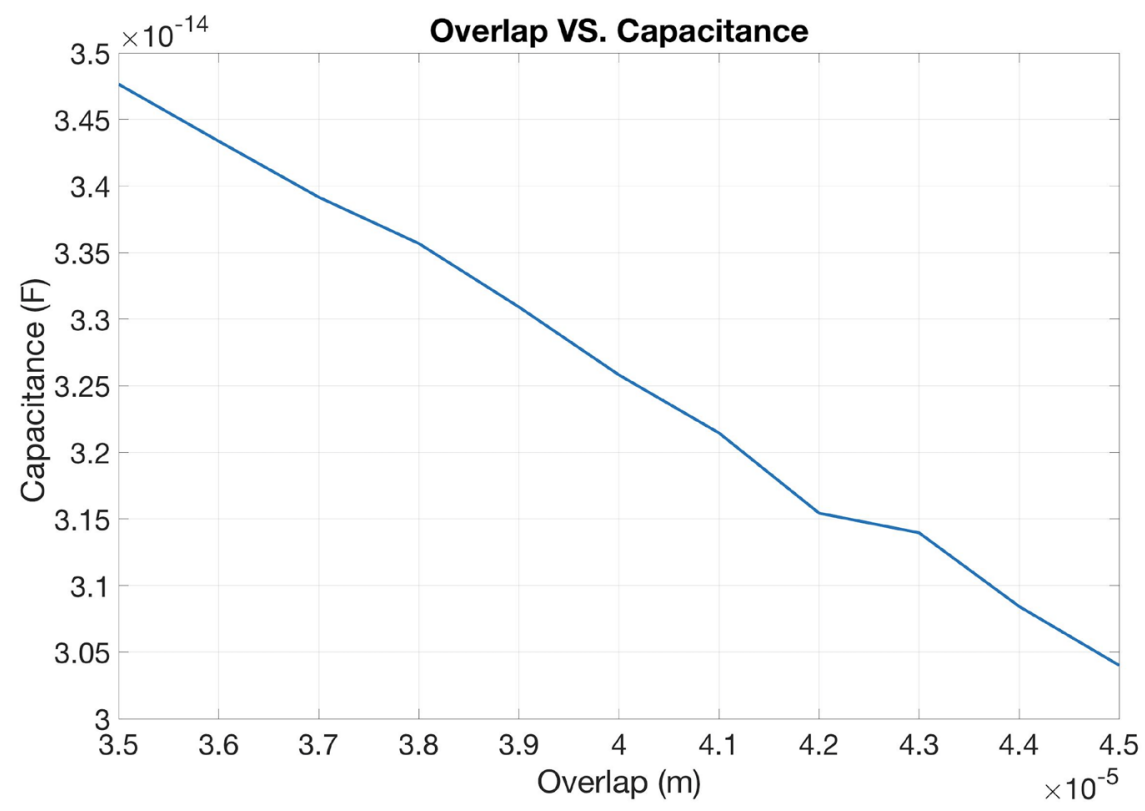

Figure 6. Overlap versus capacitance.

Table 3. The difference between the displacement before and after the optimization.

\begin{tabular}{|c|c|c|c|c|}
\hline \multirow[t]{12}{*}{$\begin{array}{l}\text { The difference } \\
\text { between the } \\
\text { displacement } \\
\text { before and after } \\
\text { the optimization. }\end{array}$} & $\begin{array}{l}\text { Applied } \\
\text { force }\end{array}$ & $\begin{array}{l}\text { Displacement } \\
\text { field PD }\end{array}$ & $\begin{array}{l}\text { Displacement } \\
\text { field OD }\end{array}$ & Difference \\
\hline & 0 & 0 & 0 & 0 \\
\hline & 1.00 & 0.04216233 & 0.042133753 & 285,769 \\
\hline & 2.00 & 0.08432466 & 0.084267506 & 571,538 \\
\hline & 3.00 & 0.12648699 & 0.126401259 & 857,307 \\
\hline & 4.00 & 0.16864932 & 0.168535012 & $11,430.8$ \\
\hline & 5.00 & 0.21081165 & 0.210668766 & $14,288.5$ \\
\hline & 6.00 & 0.25297398 & 0.252802519 & $17,146.1$ \\
\hline & 7.00 & 0.29513631 & 0.294936272 & $20,003.8$ \\
\hline & 8.00 & 0.33729864 & 0.337070025 & $22,861.5$ \\
\hline & 9.00 & 0.37946097 & 0.379203778 & $25,719.2$ \\
\hline & 10.00 & 0.42162330 & 0.421337531 & $28,576.9$ \\
\hline
\end{tabular}

where $S$ is the effective area, and d is the effective distance between two capacitor plates. Figure 7 indicates that as overlap grows, the capacitance of the comb drive will decrease. The change of capacitance can be easily measured by the voltage of the comb drive. This is how we interpreter the vibration in mechanics to electric signal.

Figure 8(a) and Figure 8(b) show the electric equilibrium state of the deformed comb drive applied with $1 \mathrm{~V}$ voltage. The arrows represent the electric 


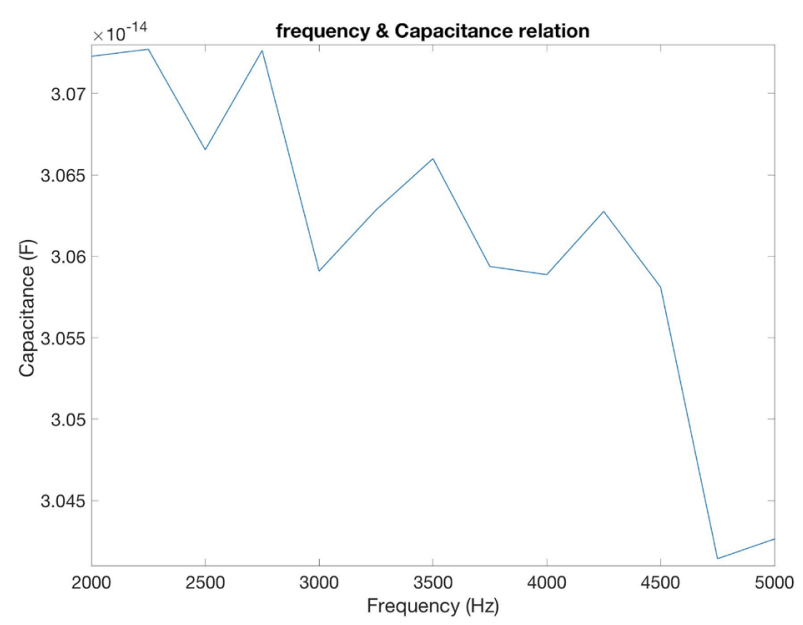

Figure 7. The capacitances at different frequencies ranged from $2000 \mathrm{~Hz}$ to $5000 \mathrm{~Hz}$.

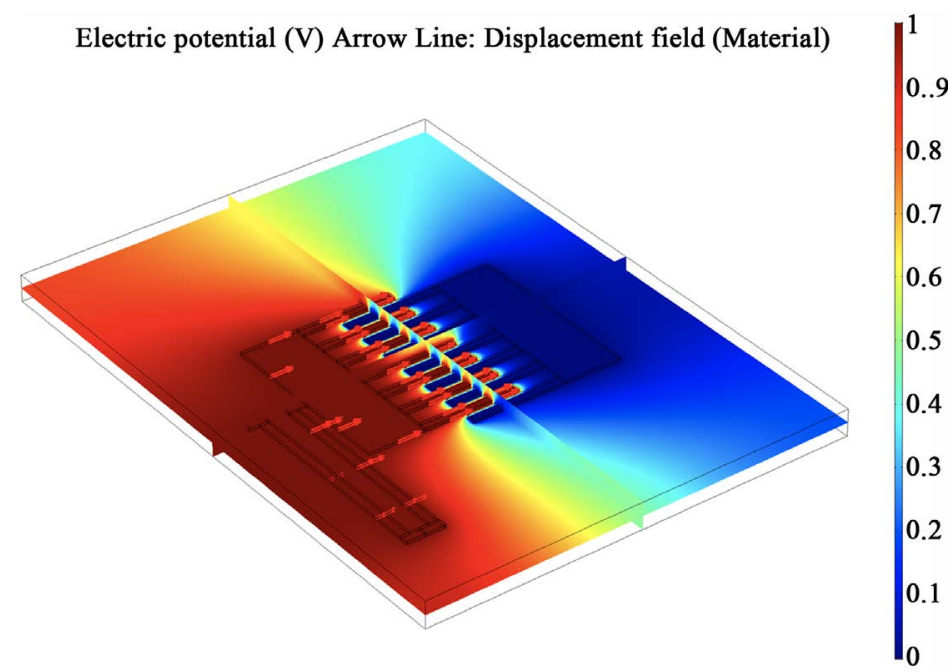

(a)

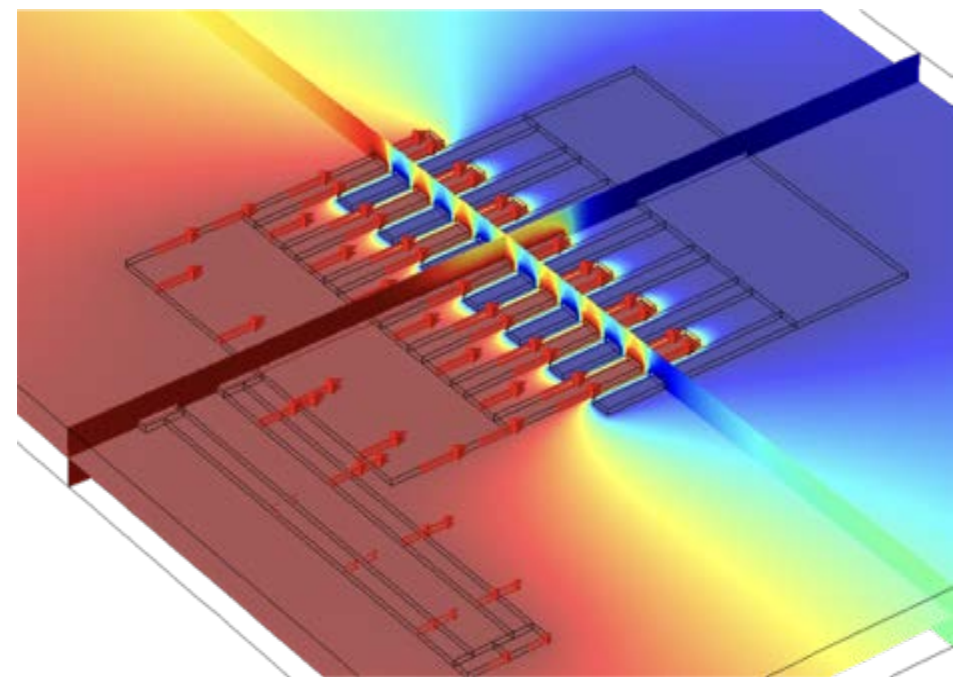

(b)

Figure 8. (a) and (b) show the electric field potential in this device. (a) The electric potential in the whole device; (b) The electric potential in a part of the device. 
field and the color represents the electric potential. As the movement of the device is to the right, the displacement field is positive. This figure is clear to show the distribution of the electric field in the comb drive device.

\section{Conclusion}

In this work, comb drive devices in rocket camber were designed, optimized, simulated and tested with a fully coupled FEA model. The model realized the visualization to help the design and optimization. The OD performed order of magnitude higher sensitive in the frequency range of the working rocket chamber. The parameterization helped to change the variables quickly in this model and made it convenient for the optimization. After the optimization, the electric filed response had been tested by comparing with the PD model and OD model. The PD had larger electric signal in response to the mechanical vibration.

\section{References}

[1] Wiak, S., Smółka, K., Dems, M. and Komęza, K. (2006) Numerical Modeling of 3D Intelligent Comb Drive Accelerometer Structure: Mechanical Models. COMPEL-The International Journal for Computation and Mathematics in Electrical and Electronic Engineering, 25, 697-704. https://doi.org/10.1108/03321640610666862

[2] Hirano, T., et al. (1992) Design, Fabrication, and Operation of Submicron Gap Comb-Drive Microactuators. Journal of Microelectromechanical Systems, 1, 52-59. https://doi.org/10.1109/84.128056

[3] Xie, H., Erdmann, L., Jing, Q. and Fedder, G.K. (2000) Simulation and Characterization of a Cmos Z-Axis Microactuator with Electrostatic Comb Drives. Proc. 3rd Int'l. Conf. on Modeling and. Simulation of Microsystems (MSM 2000), San Diego, CA, 27-29 March 2000, 181-184.

[4] Xie, H. and Fedder, G.K. (2002) Vertical Comb-Finger Capacitive Actuation and Sensing for CMOS-MEMS. Sensors and Actuators A: Physical, 95, 212-221. https://doi.org/10.1016/S0924-4247(01)00740-3

[5] Xie, H. and Fedder, G.K. (2000) A CMOS Z-Axis Capacitive Accelerometer with Comb-Finger Sensing. Micro Electro Mechanical Systems 2000 (MEMS 2000), The Thirteenth Annual International Conference on IEEE, Miyazaki, Japan, 23-27 Jan 2000, 496-501.

[6] Hah, D., Huang, S.T.Y., Tsai, J.C., Toshiyoshi, H. and Wu, M.C. (2004) Low-Voltage, Large-Scan Angle MEMS Analog Micromirror Arrays with Hidden Vertical Comb-Drive Actuators. Journal of Microelectromechanical Systems, 13, 279-289. https://doi.org/10.1109/JMEMS.2004.825314

[7] Sun, Y., Fry, S.N., Potasek, D.P., Bell, D.J. and Nelson, B.J. (2005) Characterizing Fruit Fly Flight Behavior Using a Microforce Sensor with a New Comb-Drive Configuration. Journal of Microelectromechanical Systems, 14, 4-11. https://doi.org/10.1109/JMEMS.2004.839028 